\title{
Barcode based Student Attendance System
}

\author{
K.Lakshmi Sudha \\ Research Scholar \\ Sathyabama University, \\ SIES Graduate School \\ Technology, Navi Mumbai, \\ India
}

\author{
Shirish Shinde \\ Department of Information \\ Technology \\ SIES Graduate School \\ Technology, Navi Mumbai, \\ India
}

\author{
Titus Thomas \\ Department of Information \\ Technology \\ SIES Graduate School \\ Technology, Navi Mumbai, \\ India
}

\author{
Aris Abdugani \\ Department Of Information Technology \\ Sies Graduate School Technology \\ Navi Mumbai, India
}

\begin{abstract}
Student attendance play significant role in order to justify academic outcome of a student and college as overall. Unfortunately, there is no automated attendance record keeping application available in colleges. There is a need for a tool to systematically keep the students attendance record due to increasing number of college students

The project that we are going to make is to help the teachers in our college to avoid maintaining the registry book. This project uses a barcode scanner. B.B.S.A.S uses Barcode scanner to take the attendance of students entering the lab. Each student's ID card will have a barcode at the back side of it. This barcode contains unique data of the student such as roll number, branch and year. Etc. Student will scan their barcode at the end so that the student can't cheat. The display screen will show the attendance of the particular student after scanning his/her barcode. Teachers and administrator will only have access to the system with their respective login ID's and passwords.
\end{abstract}

\section{General Terms}

Barcode Scanner, ID card

\section{Keywords}

Login Id, Defaulter, Barcode, Lab

\section{INTRODUCTION}

Barcode Based Student Attendance System"(B.B.S.A.S) is a software which utilizes barcode scanner to record and maintain the attendance of the students. The main hardware that is to be used is the barcode scanner. This barcode scanner is used in order to read a barcode. A Barcode is a machinereadable representation of information in a visual format. A bar code consists of a series of parallel, adjacent bars and spaces.

The types of Barcode are:

\section{Linear barcodes:}

A first generation, "one dimensional" barcode that is made up of lines and spaces of various widths that create specific patterns.

\section{Matrix barcodes:}

A matrix barcode, also termed as a $2 \mathrm{D}$ barcode or simply a 2D code, is a two-dimensional way to represent information. It is similar to a linear (1-dimensional) barcode, but can represent more data per unit area.

These barcodes are read using a device called as the barcode scanner.

There are different types of Barcode Scanners:

\section{Pen Type Reader:}

Pen-type readers consist of a light source and photodiode that are placed next to each other in the tip of a pen or wand. It is the cheapest barcode scanner available in market

\section{CCD Reader:}

CCD readers use an array of hundreds of tiny light sensors lined up in a row in the head of the reader. Each sensor measures the intensity of the light immediately in front of it.

\section{Smartphone Cameras:}

Smartphone cameras have the ability to read both QR codes (which automatically take you to a website URL) as well as scanning a barcode to bring up product information such as price comparisons and user reviews.

\section{Handheld Scanner:}

It is a scanner with a handle and typically a trigger button for switching on the light source.

Automatic reader:

A back office equipment to read barcoded documents at high speed (50,000/hour).[2],[3]\&[8]

\section{RELATED WORK}

A notable work has done by Hema Subramaniam, Marina Hassan, Setyawan Widyarto on "Student Attendance System (SAS)" at Sekolah Menengah Kebangsaan (SMK) DatoHarun, Kuala Selangor, Malaysia.[1]-[6] 
This paper was published in 2013, in TICOM journal. This paper explained how to replace the manual attendance recording process at schools in Malaysia. SAS can reduce the time spent by teacher in calculating the percentage of attendance for a student as well as for a class. SAS been implemented into one of the secondary school in Selangor state of Malaysia. The student already been equipped with student card which contain bar code. Student attendance recording process been assigned to the people who responsible to add the data. User acceptance testing conducted among few user categories before the system being released into the production. The measurement is on the satisfaction of the user towards student attendance system. Qualitative analysis used in determining the effectiveness of the system. Interview method used to gather the information on the user satisfaction. School attendance determines the academic achievement of a student.

An application required by most of the schools in Malaysia in order to ensure efficient attendance record keeping. Student attendance system (SAS) that developed for secondary school expected to replace the manual attendance recording process at schools in Malaysia. SAS can reduce the time spent by teacher in calculating the percentage of attendance for a student as well as for a class. In a click of button teacher can generate report at any point of time. Moreover, student's image which displayed after the scanning process expected to help teacher identify students before record their attendance. During SAS launching session, user acceptance test has been conducted and feedback from potential users being gathered. Feedback given by users highlighted few issues that need a consideration from SAS development team. [3]\&[4]

\section{NEED OF PROJECT}

The purpose of this "Barcode Based Student Attendance System (B.B.S.A.S)" software project is same as it name, i.e. it is used for the recording or marking the attendance of students for the specific day during practical. It is developed to manage the attendance information, so that college can access accurate attendance information quickly and easily as and when required, thereby improving its operational efficiency and effectiveness. Computerized software system with hardware interaction help to fulfill these goals. Computerization of the official work will help in doing a lot of manual work quickly. It will help in easy storage and access of all information, in short period of time. The development of this software project also facilitates the general administrator system to manage information of attendance of employees as well as employee records exist in organization and also can access accurate information correctly and easily which leads to increase efficiency \& effectiveness of the organization too. This project reduces the amount of work the professors have to do. The professors will not have to mark attendance manually by calling out the students name individually. The professors will not have to create a defaulters list manually as this will be done automatically by our system, which generates a defaulters list when the student attendance falls below $75 \%$. The entire process of marking attendance using our system reduces the probability of human error. The project reduces the time required for the entire process of marking the attendance as the attendance is marked automatically once the student scans his/her barcode instead of the professor marking the attendance manually by calling out the name of the student and marking their attendance in the register.[6]\&[7]

\section{PROPOSED SYSTEM}

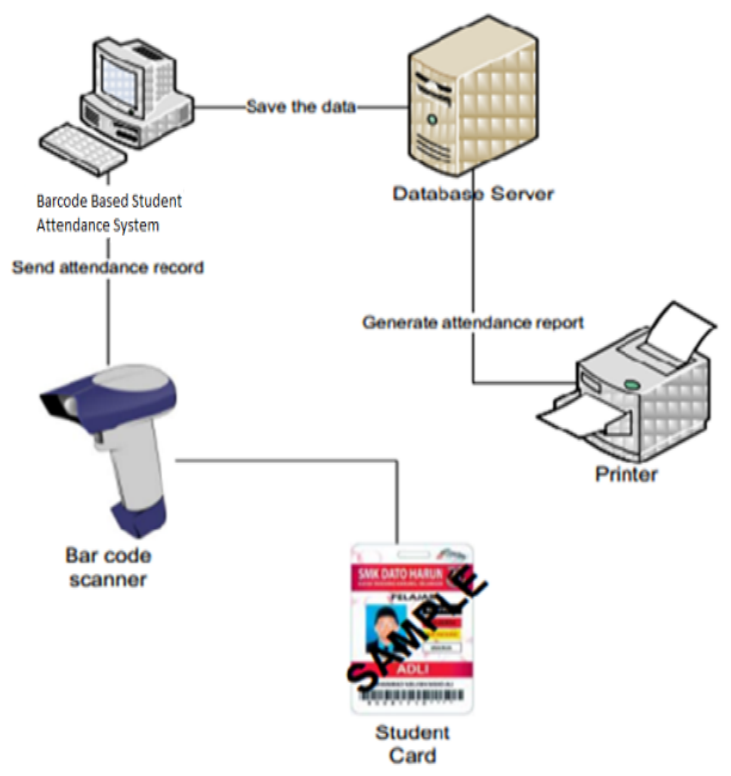

Working:

Fig 1. Architecture of our system

Attendance in colleges is generally paper based which may sometimes cause errors. Taking attendance manually consumes more time. So the proposed attendance system uses Barcode reader to take attendance. In this system, each student is issued a barcode tag. B.B.S.A.S use Barcode reader, Barcode tags and a computer with the software which stores the database about the entire details of the student's.[5]

Barcode scanners consist of three different parts including the illumination system, the sensor, and the decoder. In general, a barcode scanner "scans" the black and white elements of a barcode by illuminating the code with a red light, which is then converted into matching text. More specifically, the sensor in the barcode scanner detects the reflected light from the illumination system (the red light) and generates an analog signal that is sent to the decoder. The decoder interprets that signal, validates the barcode using the check digit, and coverts it into text. [9]

This Text that has been converted is then stored at the particular place where we desire it to be stored. The Barcode reader that we are going to use directly converts the barcode into Characters and this character is shown on the computer where the cursor s pointed at that particular moment. This data that is read form the barcode is usually the Student Personal Roll Number which identifies every individual student. This Student PRN is then used to mark attendance of that particular student for that particular lecture.[2]

The entire time table and the details of the student PRN is stored within the database. This can be used to mark attendance without any problem for the user of B.B.S.A.S.[3] 


\section{RESULTS}

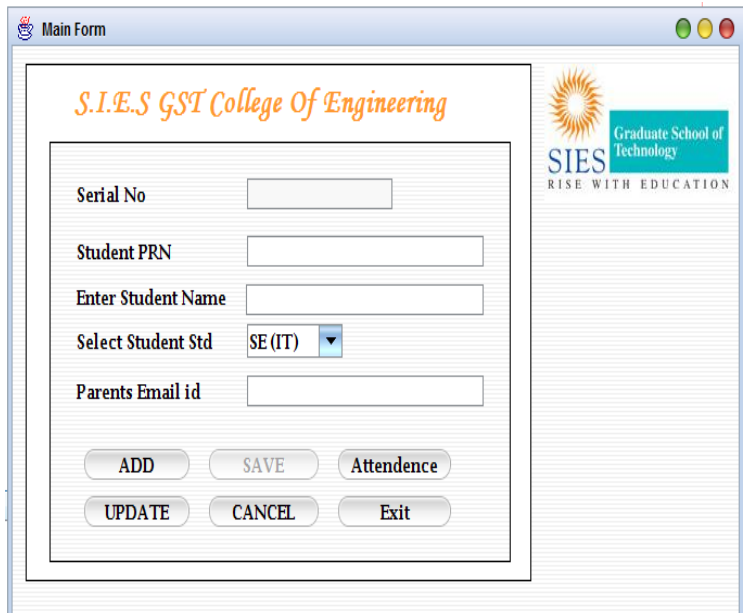

Fig 2. Main Page

The system begins with the main page were the details of the new students are inserted which would be stored in the database. It also contains a module which gives us the option to update details of the student information. The other module is that of attendance. This module has many sub modules via Attendance, Attendance chart, Defaulters, Time Table and Mark Attendance which is shown in the below screen shot.

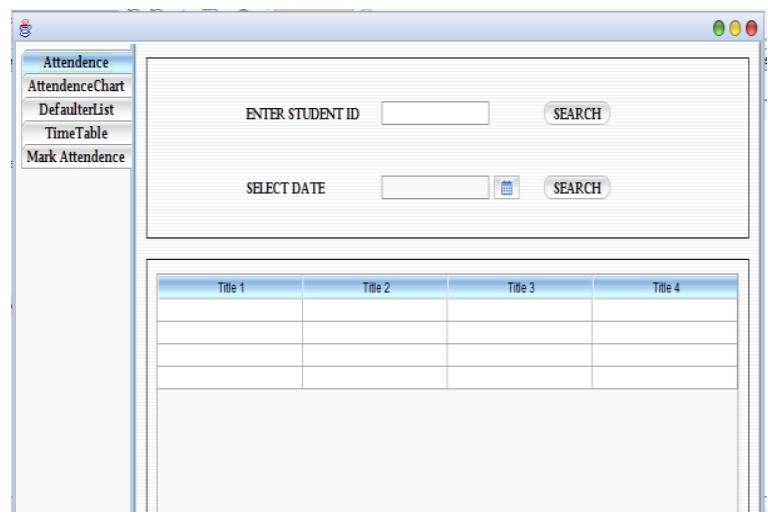

Fig 3. Sub Module Attendance.

The Attendance module displays the attendance that has been recorded in the database. We need to enter the particular date of which we need to display the attendance of that particular student.

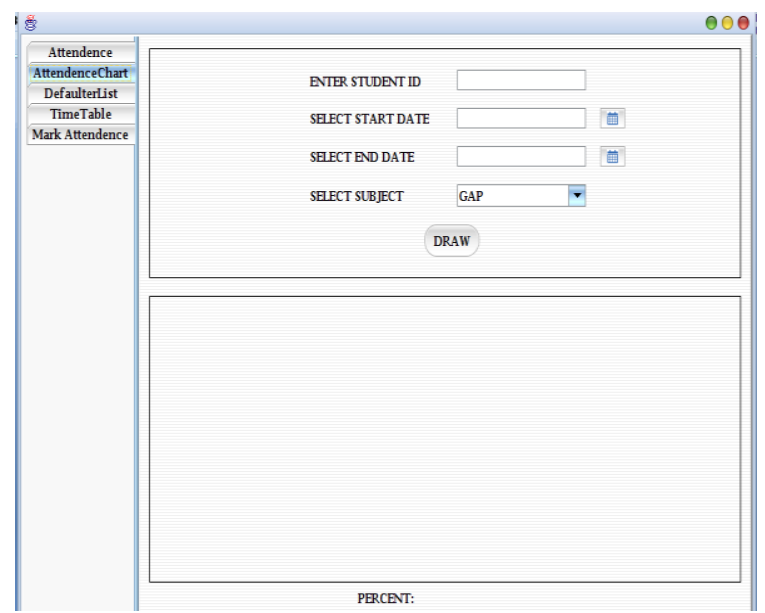

Fig 4. Sub module Attendance Chart
This module shows the entire attendance of the particular student in the form of a pie chart. This is a more interactive way to display the student's attendance. This module takes in the start date and the end date and displays the attendance of the student in that particular subject.

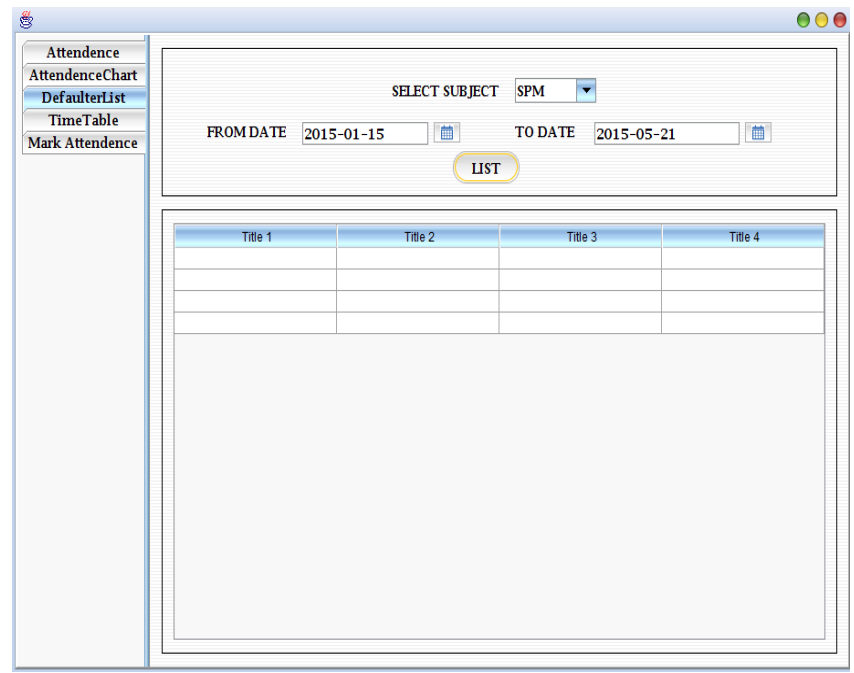

Fig 5. Sub Module Defaulter List

This is the most important module. Since this module is used in order to calculate the students attendance in percentage and if the percent is less than 75 then that particular student would be marked defaulter for that particular subject and his name would be displayed in this module.

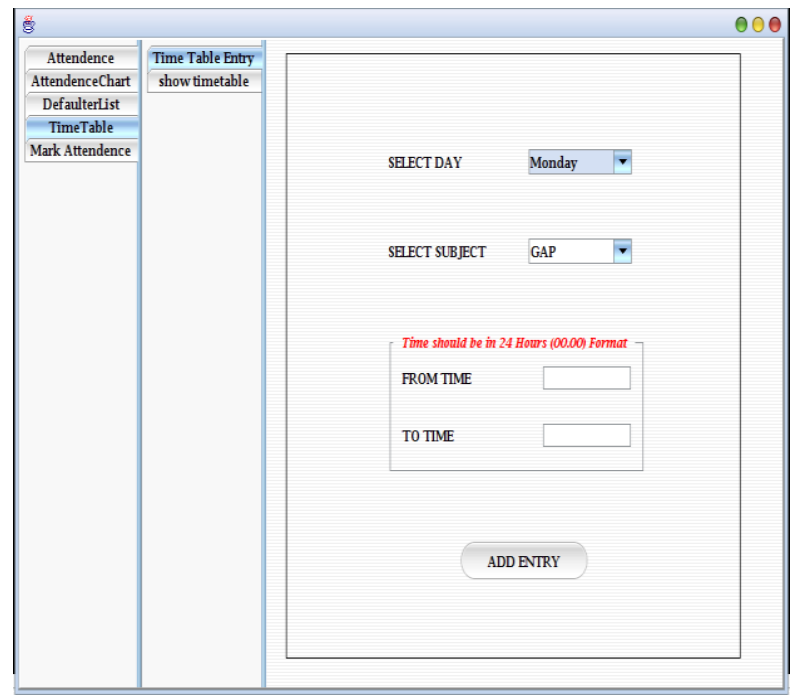

Fig 6. Sub Module Time Table

Since time table changes every year we need a module to keep on updating the time table accordingly. This Module is used to enter the entire detail of the time table into the database. 


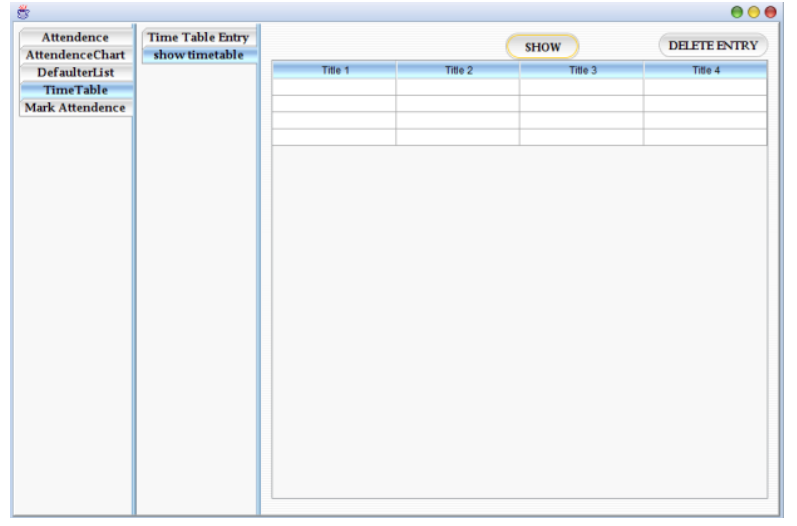

Fig 7. Sub module Show Time Table

This module displays the entire time table that has been stored in the database. This allows the user to check the system if there is some error in the time table that has been entered earlier and if there is a need to make any changes.

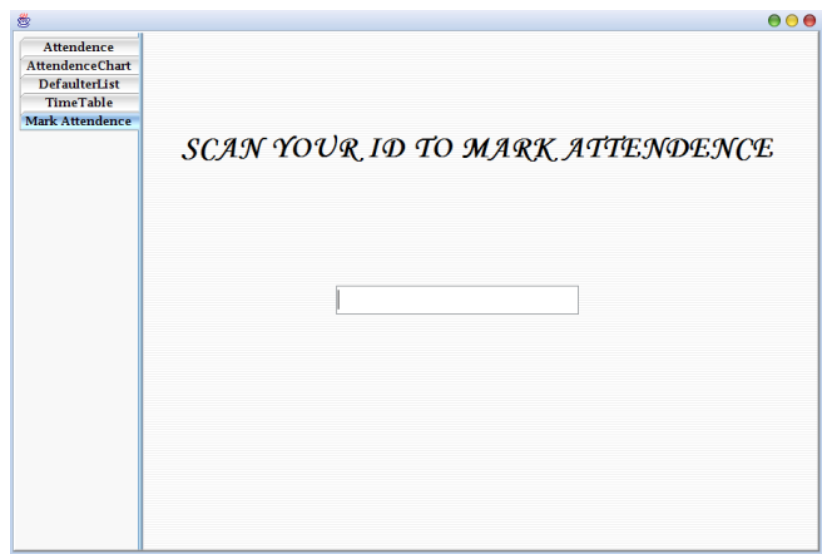

Fig 8. Sub module Mark Attendance

This module is which would be used to mark the attendance using the barcode reader. The blank box is the place where the barcode reader will read and store the characters that it has read from the barcode tags.

\section{ACKNOWLEDGEMENT}

This research was supported by Sies Graduate school technology. We thank our colleagues who provided insight and expertise that greatly assisted the research.

We thank K.Lakshmi Sudha for assistance and for comments that greatly improved the manuscript.

Lastly, thanks to our parents for all the moral support and the amazing chances they've given us over the years.

\section{CONCLUSION}

Thus we have developed java application which would help marking attendance using the barcode scanner.
It will reduce the teacher's efforts to manually mark attendance and their headache of maintaining the register since everything would be stored in the database.

It will also help in generating the defaulters list on its own and send email to those students whose attendance is below the required amount.

\section{REFERENCES}

[1] A.S.Bedi and J.H.Marshall, "Primary school attendance in Honduras," Journal of Development Economics, vol. 69, pp. 129-153, 2002

[2] T.S.Lim, S.C.Sim, and M.M.Mansor, "RFID based attendance system," 2009 IEEE Symosium on Industrial Electronics and Applications, no. Isiea, pp. 778-782, Oct. 2009

[3] M.Kassim, H.Mazlan, N.Zaini, and M.K.Salleh, "Webbased student attendance system using RFID technology," 2012 IEEE Control and System Graduate Research Colloquium, no. Icsgrc, pp. 213-218, Jul. 2012.

[4] M.K.Y.Sabri, M.Z.A.A.Aziz, M.S.R.M.Shah, and M.F.A.Kadir, "Smart Attendance System by using RFID” figure 2, 2007.

[5] A.Qaiser and S. A. Khan, "Automation of Time and Attendance using RFID Systems," no. November, pp. 13-14, 2006.

[6] T.-C. Li, H.-W. Wu, and T.-S. Wu, "The Study of Biometrics Technology Applied in Attendance Management System," 2012 Third International Conference on Digital Manufacturing \& Automation, pp. 943-947, Jul. 2012.

[7] I.A.Ujan and I.A.Ismaili, "Biometric attendance system," The 2011 IEEE/ICME International Conference on Complex Medical Engineering, pp. 499-501, May 2011.

[8] Z.Yongqiang and L. Ji, "The Design of Wireless Fingerprint Attendance System," 2006 International Conference on Communication Technology, pp. 1-4, Nov. 2006.

[9] H. Oktavianto, "Image-based Intellligent Attendance Logging System,” pp. 1-6, 2012.

[10] M. I. Moksin and N. M. Yasin, "The Implementation of Wireless Student Attendance System in an Examination Procedure," 2009 International Association of Computer Science and Information Technology - Spring Conference, pp. 174$177,2009$.

[11] Hema Subramaniam, Marina Hassan \& Setyawan Widyarto,"Bar Code Scanner Based Student Attendance System (SAS)," Journal TICOM, Vol.1, No.3 Mei,2013.

[12] BARCODE SCANNERS: HOW DO THEY WORK?http://www.waspbarcode.com/buzz/howbarcode-scanners-work/ 